Check for updates

Cite this: Chem. Sci., 2018, 9, 4308

\title{
Kinetic studies on strand displacement in de novo designed parallel heterodimeric coiled coils $\uparrow$
}

\begin{abstract}
Mike C. Groth, ${ }^{a}$ W. Mathis Rink, (D) a Nils F. Meyer ${ }^{a}$ and Franziska Thomas (D) *ab
Among the protein folding motifs, which are accessible by de novo design, the parallel heterodimeric coiled coil is most frequently used in bioinspired applications and chemical biology in general. This is due to the straightforward sequence-to-structure relationships, which it has in common with all coiled-coil motifs, and the heterospecificity, which allows control of association. Whereas much focus was laid on designing orthogonal coiled coils, systematic studies on controlling association, for instance by strand displacement, are rare. As a contribution to the design of dynamic coiled-coil-based systems, we studied the strand-displacement mechanism in obligate heterodimeric coiled coils to investigate the suitability of the dissociation constants $\left(K_{D}\right)$ as parameters for the prediction of the outcome of strand-displacement reactions. We use two sets of heterodimeric coiled coils, the previously reported $N-A_{x} B_{y}$ and the newly characterized $C-A_{x} B_{y}$. Both comprise $K_{D}$ values in the $\mu M$ to sub-nM regime. Strand displacement is explored by $C D$ titration and a FRET-based kinetic assay and is proved to be an equilibrium reaction with half-lifes from a few seconds up to minutes. We could fit the displacement data by a competitive binding model, giving rate constants and overall affinities of the underlying association and dissociation reactions. The overall affinities correlate well with the ratios of $K_{D}$ values determined by $C D$-thermal denaturation experiments and, hence, support the dissociative mechanism of strand displacement in heterodimeric coiled coils. From the results of more than 100 different displacement reactions we are able to classify three categories of overall affinities, which allow for easy prediction of the equilibrium of strand displacement in two competing heterodimeric coiled coils.
\end{abstract}

Received 17th December 2017

Accepted 14th April 2018

DOI: $10.1039 / \mathrm{c} 7 \mathrm{sc} 05342 \mathrm{~h}$

rsc.li/chemical-science coiled-coil motif has found widespread use in the design of biomimetic systems, ${ }^{8}$ such as dimerization domain in an engineered EGF receptor ${ }^{9}$ or recognition motif for SNAREmediated vesicle fusion. ${ }^{\mathbf{1 0}, 11}$ Furthermore, applications as affinity tags in protein labelling ${ }^{12,13}$ or protein purification have been reported. ${ }^{14,15}$ Some peptide materials including hydrogels, cages or nanotubes are also based on the heterodimeric coiledcoil interaction as a central design element. ${ }^{16-23}$ Other applications include reaction mediation in e.g. acyl-transfer reactions, ${ }^{24-27}$ and $\mathrm{C}-\mathrm{H}$ activation. ${ }^{28}$

The simplest rules to design a parallel heterodimeric coiled coil include an isoleucine-leucine core to direct dimerization, ${ }^{29}$ and the introduction of positively charged lysines (Lys) to the $e$ and $g$ positions of one coil strand and negatively charged glutamic acid residues (Glu) to the $e$ and $g$ positions of the other coil strand to induce heterospecificity. ${ }^{30-34}$ Often, asparagine residues (Asn) at the $a$ positions of a central coiled-coil heptad are incorporated as an additional design feature to improve the dimer specificity and to stabilize the parallel orientation..$^{35-39}$ However, precise control of association and dissociation, which also includes variation of the strength of association, is highly desirable in many applications. Therefore, efforts have been made to generate orthogonal coiled coils by modulating the charge pattern of the individual coil strands, or by engineering
${ }^{a}$ Georg-August-Universität Göttingen, Institute of Organic and Biomolecular Chemistry, Tammannstraße 2, 37077 Göttingen, Germany.E-mail: fthomas@gwdg.de ${ }^{b}$ Center for Biostructural Imaging of Neurodegeneration, Von-Siebold-Straße 3a, 37075 Göttingen, Germany

$\dagger$ Electronic supplementary information (ESI) available. See DOI: $10.1039 / \mathrm{c} 7 \mathrm{sc} 05342 \mathrm{~h}$

De novo designed protein folding motifs have been increasingly bottom-up., ${ }^{1,2}$ Among the protein folds the coiled-coil mot mentioned fields. ${ }^{3,4}$ The straightforward sequence-to-structure pattern of hydrophobic $(\mathrm{h})$ and polar (p) residues - in short available for coiled-coil dimers to tetramers and higher order

Among the available coiled-coil assemblies the heterodimeric coiled coil has gained significant scientific attention. to the assembly, which makes it an ideal simplified model for protein-protein interactions. ${ }^{4}$ Therefore, the heterodimeric 
polar recognition motifs into the hydrophobic core. ${ }^{19,40-43}$ Very recently, an iterative approach to create larger sets of orthogonal heterodimeric coiled coils has been presented. ${ }^{44}$ In comparison, only little has been reported on simple rules to modulate the strength of coiled-coil association. This is important, as it allows engineering of dynamic systems, such as drug delivery devices. ${ }^{45}$ Concepts include modulation of the strengths of the salt bridges or the hydrophobic interactions by varying the lengths of the amino acid side chains at the coiled-coil interface. ${ }^{46-48}$

Recently, a set of heterodimeric coiled coils, $\mathrm{A}_{x} \mathrm{~B}_{y}$, was presented, in which the strength of coiled-coil interaction was modulated by the lengths of the individual coil strands. ${ }^{37}$ The design was mainly based on the Hodges EK peptides; ${ }^{31}$ however, the introduction of Asn at a central $a$ position was vital for enabling the formation of distinct coiled-coil assemblies, in which the individual strands varied in lengths of $3,3.5$ and 4 heptads, truncated from the $\mathrm{N}$-terminal end. Combination resulted in a set of nine heterodimeric coiled coils with dissociation constants in the $\mu \mathrm{M}$ to sub-nM regime.

The range of $K_{\mathrm{D}}$ values within the $\mathrm{A}_{x} \mathrm{~B}_{y}$ set of heterodimeric coiled coils should open new routes to the design of dynamic functional systems based on strand displacement. Indeed, $K_{\mathrm{D}}$ values have often been discussed as parameters to assess such displacement events in heterodimeric coiled coils. ${ }^{8,37,49}$ However, the mechanism has hardly been studied so far and easy models might not apply as dissociation of heterodimeric coiled coils goes along with unfolding. ${ }^{30,37}$ Until now, there is only one application reported, in which strand displacement in heterodimeric coiled coils was used to design a two-state switching system to control the interaction of proteins. ${ }^{49}$ Although displacement was discussed to be thermodynamically driven, no details on the mechanism or the underlying equilibria were revealed. To use strand displacement reliably in the design of functional systems, we need more thorough information. Furthermore, a correlation of strand-displacement equilibria to $K_{\mathrm{D}}$-value differences would be desirable to facilitate designs. Herein, we present an extensive study of strand displacement in $\mathrm{A}_{x} \mathrm{~B}_{y}$ peptides, which, for clarity reasons, we dub $\mathrm{N}-\mathrm{A}_{x} \mathrm{~B}_{y}$, and a similar set of heterodimeric coiled coils, $C-A_{x} B_{y}$, in which the individual peptides are truncated from the C-terminal end. We aim to understand the mechanism of strand displacement in heterodimeric coiled coils by performing CD-titration experiments and a FRET-based kinetic stranddisplacement assay. This leads to an easy-to-use rule of thumb to predict outcomes of strand displacements purely based on $K_{\mathrm{D}}$ values.

\section{Experimental}

\section{General}

Fmoc-protected amino acids were purchased from GL Biochem LTD (Shanghai, China). DIC and Oxyma Pure were obtained from Iris Biotech GmbH (Marktredwitz, Germany). The H-Rink Amide-ChemMatrix ${ }^{\circledR}$ resin was acquired from Sigma Aldrich (Taufkirchen, Germany). DMF used for peptide synthesis was supplied by Fisher Scientific (Schwerte, Germany) and was of peptide grade quality. Acetonitrile used for HPLC was supplied by Fisher Scientific (Schwerte, Germany) with HPLC grade quality. Water used for HPLC and reactions was obtained by purifying deionized water with the purification device Simplicity from Millipore. All other reagents were supplied by Sigma Aldrich (Taufkirchen, Germany), Thermo Fisher Scientific (Langenselbold, Germany), VWR International (Darmstadt, Germany) and Carl Roth (Karlsruhe, Germany). All reagents were of synthesis grade quality and were used as supplied. Unless otherwise stated, biophysical measurements were performed in phosphate buffered saline (PBS, $8.2 \mathrm{mM} \mathrm{Na}_{2} \mathrm{HPO}_{4}$, $1.8 \mathrm{mM} \mathrm{K}_{2} \mathrm{HPO}_{4}, 137 \mathrm{mM} \mathrm{NaCl}, 2.7 \mathrm{mM} \mathrm{KCl}, \mathrm{pH}$ 7.4). Peptide concentrations were determined by UV-absorbance at $280 \mathrm{~nm}$ $\left(\varepsilon_{280}(\right.$ Trp $)=5690 \mathrm{~mol}^{-1} \mathrm{~cm}^{-1}, \varepsilon_{280}($ Tyr $\left.)=1280 \mathrm{~mol}^{-1} \mathrm{~cm}^{-1}\right)$, and, alternatively, at $214 \mathrm{~nm}$ using a NanoDrop 2000 spectrophotometer from Thermo Scientific. Extinction coefficients at $214 \mathrm{~nm}$ were calculated according to Kuipers et al. ${ }^{50}$

\section{Peptide synthesis}

The peptide amides were synthesized on a H-Rink AmideChemMatrix ${ }^{\circledR}$ resin on a $0.1 \mathrm{mmol}$ scale on a Liberty Blue CEM microwave-assisted peptide synthesizer. The synthesis was conducted via a standard Fmoc/tBu-protocol using DIC and Oxyma Pure as coupling reagents and a solution of piperidine in DMF $(1: 4(\mathrm{v} / \mathrm{v}))$ for Fmoc-removal. $N$-Acetylation of the peptides was carried out by equilibrating the peptide resin with $5 \mathrm{~mL}$ of acetic acid anhydride/pyridine $(1: 9(\mathrm{v} / \mathrm{v}))$ for $5 \mathrm{~min}$ at room temperature. Acidic cleavage from the resin was achieved by a treatment with a mixture of trifluoroacetic acid (TFA)/ triisopropylsilane/water $(90: 5: 5(\mathrm{v} / \mathrm{v} / \mathrm{v}), 3 \mathrm{~h})$. The resin was washed with additional TFA ( $5 \mathrm{~mL})$, and the combined TFA fractions were concentrated to a third of the initial volume under a flow of nitrogen. The crude peptide was then precipitated from cold diethylether $(40 \mathrm{~mL})$ and isolated by centrifugation and decantation of the supernatant. The precipitate was washed twice with ice-cold diethylether and subsequently dissolved in $5 \mathrm{~mL}$ of a $1: 1(\mathrm{v} / \mathrm{v})$ mixture of acetonitrile and water and then freeze-dried to give a fine white solid.

\section{Peptide purification}

Peptides were purified by preparative and semi-preparative reversed-phase HPLC using a JASCO chromatography system (pumps PU-2080 Plus, degasser DG-2080-53, detector MD-


respectively, and a Nucleodur 100-5-C18 $(250 \mathrm{~mm}$ by $21 \mathrm{~mm}, 5$ $\mu \mathrm{m})$ reversed-phase column from Macherey-Nagel for preparative HPLC and a Nucleodur 100-5-C18 ec, $(250 \mathrm{~mm}$ by $10 \mathrm{~mm}, 5 \mu \mathrm{m}$ ) reversed-phase column from Macherey-Nagel for semi-preparative HPLC. Linear gradients of water and acetonitrile (buffer A: water, $0.1 \%$ TFA, buffer B: acetonitrile, $0.1 \%$ TFA) of $30-60 \%$ buffer B over 30 min for A peptides and $20-50 \%$ buffer B over 30 min for B peptides were used for purification. Chromatograms were monitored at $220 \mathrm{~nm}$ wavelengths. 


\section{Peptide characterization}

The peptides were characterized by mass spectrometry on a Bruker Autoflex Speed MALDI-TOF mass spectrometer operating in positive-ion reflector mode (matrix: $\alpha$-cyano-4hydroxycinnamic acid (CHCA), external calibration). Analytical HPLC measurements were performed using a JASCO chromatography system (pumps PU-2085 Plus, detector MD-2010 Plus, autosampler AS-2055 Plus) and a Nucleodur 100-5-C18 $(250 \mathrm{~mm}$ by $4.6 \mathrm{~mm}, 5 \mu \mathrm{m}$ ) reversed-phase column from Macherey-Nagel at a flow rate of $1 \mathrm{~mL} \mathrm{~min}^{-1}$. For peptide characterization a linear gradient of water and acetonitrile (buffer A: water, $0.1 \%$ TFA, buffer B: acetonitrile, $0.1 \%$ TFA) run from $20-80 \%$ buffer B over $20 \mathrm{~min}$ for the A peptides and 10-70\% buffer B over $20 \mathrm{~min}$ for the B peptides were used. Chromatograms were monitored at $220 \mathrm{~nm}$ wavelengths.

\section{Circular dichroism spectroscopy}

CD spectra and CD thermal-denaturation profiles were recorded on a JASCO J-1500 CD spectrometer, which was equipped with a JASCO PTC-510 temperature measuring unit. CD spectra were measured at $50 \mu \mathrm{M}$ peptide concentration in PBS at $20{ }^{\circ} \mathrm{C}$ in

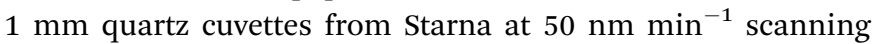
speed. CD-thermal-denaturation experiments were performed by heating from 5 to $95{ }^{\circ} \mathrm{C}$ at a heat rate of $40{ }^{\circ} \mathrm{C} \mathrm{h}{ }^{-1}$. The CD signal at $222 \mathrm{~nm}$ was recorded at $1{ }^{\circ} \mathrm{C}$ intervals $(1 \mathrm{~nm}$ interval, $1 \mathrm{~nm}$ bandwidth, $16 \mathrm{~s}$ response time). The midpoints of the thermal denaturation curves $\left(T_{\mathrm{m}}\right)$ were determined from the second derivative of the variable temperature slope. Equilibrium dissociation constants $\left(K_{\mathrm{D}}\right)$ were determined using FitDis! $1.0 .^{51}$

\section{CD-titration experiments}

Coiled-coil peptides were mixed in a $1: 1$ ratio in PBS and in $50 \mu \mathrm{M}$ concentration of the individual coil peptides. After addition of the competitor peptide in half-equimolar and equimolar amounts, CD spectra were recorded at $20^{\circ} \mathrm{C}$ in $1 \mathrm{~mm}$ quartz cuvettes from Starna at $50 \mathrm{~nm} \min ^{-1}$ scanning speed. For background correction the coil peptides were measured individually at $25 \mu \mathrm{M}$ and $50 \mu \mathrm{M}$ concentration. To process the mixing experiments, the obtained CD spectra were corrected by the CD spectra of the individual peptide, which was displaced in the experiment.

\section{FRET-assay to determine strand-displacement kinetics}

The experiments were performed on a Clariostar plate reader from BMG Labtech equipped with a $1 \mathrm{~mL}$ dispenser in black Microfluor 196 well plates from Thermo Scientific. Prior to experiment, the well plates were equilibrated with a solution of Roche Blocking Reagent in PBS $\left(1 \mathrm{mg} \mathrm{mL}{ }^{-1}, 300 \mu \mathrm{L}\right.$ per well) for $2 \mathrm{~h}$ at $25^{\circ} \mathrm{C}$. Afterwards, the well plates were washed three times with $100 \mu \mathrm{L}$ PBS. The fluorescently labelled heterodimeric coiled coils (see Tables S1 and $\mathrm{S} 2 \dagger$ entries 7 to 12) were equilibrated in $15 \mu \mathrm{M}$ concentration in a $1: 1$ ratio in PBS, first at $25{ }^{\circ} \mathrm{C}$ for $1 \mathrm{~h}$, and then at $4{ }^{\circ} \mathrm{C}$ over night.
Strand-displacement experiments were performed as triple measurements and monitored over $60 \mathrm{~s}$ as a decrease of the FRET-acceptor fluorescence $\left(\lambda_{\mathrm{ex}}=270 \mathrm{~nm}, \lambda_{\mathrm{em}}=540 \mathrm{~nm}\right)$ upon addition of equimolar amounts of a non-labelled competitor peptide $\left(\mathrm{P}_{\text {comp }}\right)$. To obtain minimum fluorescence $\left(F_{\min }\right)$, another $50 \mu \mathrm{M} \mathrm{P}_{\text {comp }}$ were added. The obtained data was baseline-corrected by $F_{\text {min }}$, normalized to $F_{\max }$ and fit to a single exponential decay function using OriginPro 8.5G (eqn (1)),

$$
F=F_{\text {eq }}+A \mathrm{e}^{-k_{\text {obs }} / t}
$$

where $F_{\text {eq }}$ is the fluorescence at equilibrium, $A$ the preexponential factor and $k_{\text {obs }}$ the observed rate constant. Halflifes were calculated according to eqn (2).

$$
t_{1 / 2}=\frac{\ln 2}{k_{\mathrm{obs}}}
$$

Analysis of the kinetic data was performed by fitting the fluorescence data to a competitive binding model using the program DynaFit. ${ }^{52,53}$ DynaFit uses a general numerical method for the determination of rate constants that characterizes simultaneous and competitive binding of a ligand to two receptors presuming a dissociative pathway for receptor displacement. In the context of heterodimeric coiled coils of the type $\mathrm{AB}$ the competing receptors can be regarded as $\mathrm{A}$ and $\mathrm{A}_{\text {comp }}$ or as $\mathrm{B}$ and $\mathrm{B}_{\text {comp }}$, respectively. Therefore, strand displacement can be described as follows:

$$
\mathrm{A}+\mathrm{B} \underset{k_{2}}{\stackrel{k_{1}}{\rightleftarrows}} \mathrm{AB}
$$

$$
\mathrm{A}+\mathrm{B}_{\text {comp }} \underset{k_{4}}{\stackrel{k_{3}}{\rightleftarrows}} \mathrm{AB}_{\text {comp }} \text { or } \mathrm{A}_{\text {comp }}+\mathrm{B} \underset{k_{4}}{\stackrel{k_{3}}{\rightleftarrows}} \mathrm{A}_{\text {comp }} \mathrm{B}
$$

To create the input files for DynaFit, kinetic fluorescence data was converted into concentration of free A or B in the time course of the experiment and competitive reformation of the $\mathrm{AB}$ coiled coil. $F_{\max }$ was assigned to zero conversion of the initial AB coiled-coil complex ( $15 \mu \mathrm{M} \mathrm{AB}$ and $\left.15 \mu \mathrm{M} \mathrm{P}_{\text {comp }}\right)$ and $F_{\min }$ was assigned to full strand displacement in $\mathrm{AB}\left(15 \mu \mathrm{M} \mathrm{AP}_{\text {comp }}\right.$ or $\mathrm{P}_{\text {comp }} \mathrm{B}$ and $15 \mu \mathrm{M} \mathrm{A}$ or $\left.\mathrm{B}\right)$ to $\mathrm{AB}_{\text {comp }}$ or $\mathrm{A}_{\text {comp }} \mathrm{B}$, respectively. Same strand-displacement kinetics for coiled coils of the same lengths of the individual strands were presumed whether labelled or unlabelled. Fitting of displacement of A or B from the initial $\mathrm{AB}$ complex and re-association, gave relative rate constants $k_{1}$ to $k_{4}$ from which the overall affinities $\left(k_{1} k_{4} / k_{2} k_{3}\right)$ were calculated.

\section{Results and discussion}

\section{A set of C-terminally truncated heterodimeric coiled coils}

The coiled-coil stability increases with the lengths of the coiledcoil strands as shown for a set of homodimeric coiled coils with chain lengths of one to five heptads. ${ }^{54}$ This can readily be exploited to generally tune the $K_{\mathrm{D}}$ values of coiled coils. Recently, a set of heterodimeric coiled coils was presented that 
Table 1 Sequences of $\mathrm{N}-\mathrm{A}_{x} \mathrm{~B}_{y}$ and $\mathrm{C}-\mathrm{A}_{x} \mathrm{~B}_{y}$ peptides $^{a}$

\begin{tabular}{|c|c|c|c|c|c|}
\hline & & quence and & heptad regis & $\operatorname{ster}^{b}$ & \\
\hline & gabcdef & gabcdef & gabcdef & gabcdef & \\
\hline $\mathrm{N}-\mathrm{A}_{3} \mathrm{~B}_{3}$ & G & EIAALEK & ENAALEW & EIAALEQ & GG \\
\hline & G & $\mathrm{KI}$ & $\mathrm{KNZ}$ & $\mathrm{KIA}$ & GG \\
\hline $\mathrm{N}-\mathrm{A}_{3.5} \mathrm{~B}_{3.5}$ & $\mathrm{LEQ}$ & $E I$ & ENZ & EIA & GG \\
\hline & LKQ & KIA & KNA & $\mathrm{KIA}$ & GG \\
\hline$A_{4} B_{4}$ & G EIAALEQ & EIAALEK & ENAALEW & EIAALEQ & \\
\hline & G KIAALKQ & KIAALKY & $\mathrm{KNA}$ & KIAALKQ & GG \\
\hline$C-A_{3.5} B_{3.5}$ & G EIAALEQ & EIAALEK & ENAALEW & EIAA & GG \\
\hline & G KIAALKQ & KIAALKY & KNAALKK & KIAA & GG \\
\hline$C-A_{3} B_{3}$ & G EIAALEQ & EIAALEK & ILEW & & $\mathrm{G}$ \\
\hline & G KIAALKQ & KIAALKY & KNAALKK & & GG \\
\hline
\end{tabular}

${ }^{a}$ For reasons of clarity only the blunt-ended pairs are presented. Combinations of coil strands of different lengths within the $\mathrm{N}$ - and C-truncated sets were also studied. ${ }^{b}$ Peptides were synthesized as C-terminal amides and were acetylated at the N-termini.

covered dissociation constants from micromolar to subnanomolar concentration (Table 1) as a result from pairing coil strands of 3, 3.5 and 4 heptads in lengths. ${ }^{37}$ Key to the design was a buried asparagine (Asn) pair that not only increased dimer specificity but more importantly aligned the assemblies to form blunt ends at the C-termini and staggered ends at the $\mathrm{N}$-termini. In the following, this set will be dubbed $\mathrm{N}$-truncated set of heterodimeric coiled coils, short $\mathrm{N}-\mathrm{A}_{x} \mathrm{~B}_{y}$ with $x$ and $y$ indicating the lengths of the coil strands, respectively.

Heterodimeric coiled coils have been widely used as association-mediating tools in biological and biophysical applications. $^{4,55}$ To introduce them to e.g. biomolecules or surfaces the termini of the coil strands are most commonly addressed. Coiled-coil assemblies with sticky-ended N-termini can complicate designs which rely on $\mathrm{N}$-terminal modification. Therefore, we considered a similar set of heterodimeric coiled coils with varying lengths at the C-termini, $\mathrm{C}-\mathrm{A}_{x} \mathrm{~B}_{y}$, as valuable addition to the existing set of heterodimeric coiled-coil building blocks. C- $\mathrm{A}_{x} \mathrm{~B}_{y}$ sequences were designed following the rules for $\mathrm{N}-\mathrm{A}_{x} \mathrm{~B}_{y},{ }^{37}$ with the difference that the sequences were shortened from the $\mathrm{C}$-terminal and not from the $\mathrm{N}$-terminal end. In analogy to $\mathrm{N}-\mathrm{A}_{x} \mathrm{~B}_{y}$, we chose similar chain lengths and generated a set of nine heterodimeric coiled coils with exclusively blunt-ended $\mathrm{N}$-termini and in parts staggered C-termini (Table 1).

Peptides were synthesized using microwave-assisted Fmoc/ $t \mathrm{Bu}$-based solid-phase peptide synthesis and were studied for structure and thermal stability by circular dichroism (CD) spectroscopy. CD spectra of all nine possible combinations of heterodimeric coiled coils show 58 to $85 \% \alpha$-helical structure displayed by the characteristic strong minima at 208 and $222 \mathrm{~nm}$ (Fig. 1A and C). Similar to $\mathrm{N}-\mathrm{A}_{x} \mathrm{~B}_{y}$ the $\mathrm{C}-\mathrm{A}_{x} \mathrm{~B}_{y}$ coiled coils show on-off folding, i.e. low tendency to form homomeric assemblies, with the exception of $\mathrm{B}_{4}$ which forms weak homodimers at room temperature (Fig. 1E and F).

Thermal denaturation curves were recorded at $222 \mathrm{~nm}$ in a temperature gradient from $5-90{ }^{\circ} \mathrm{C}$. All thermal denaturation
A
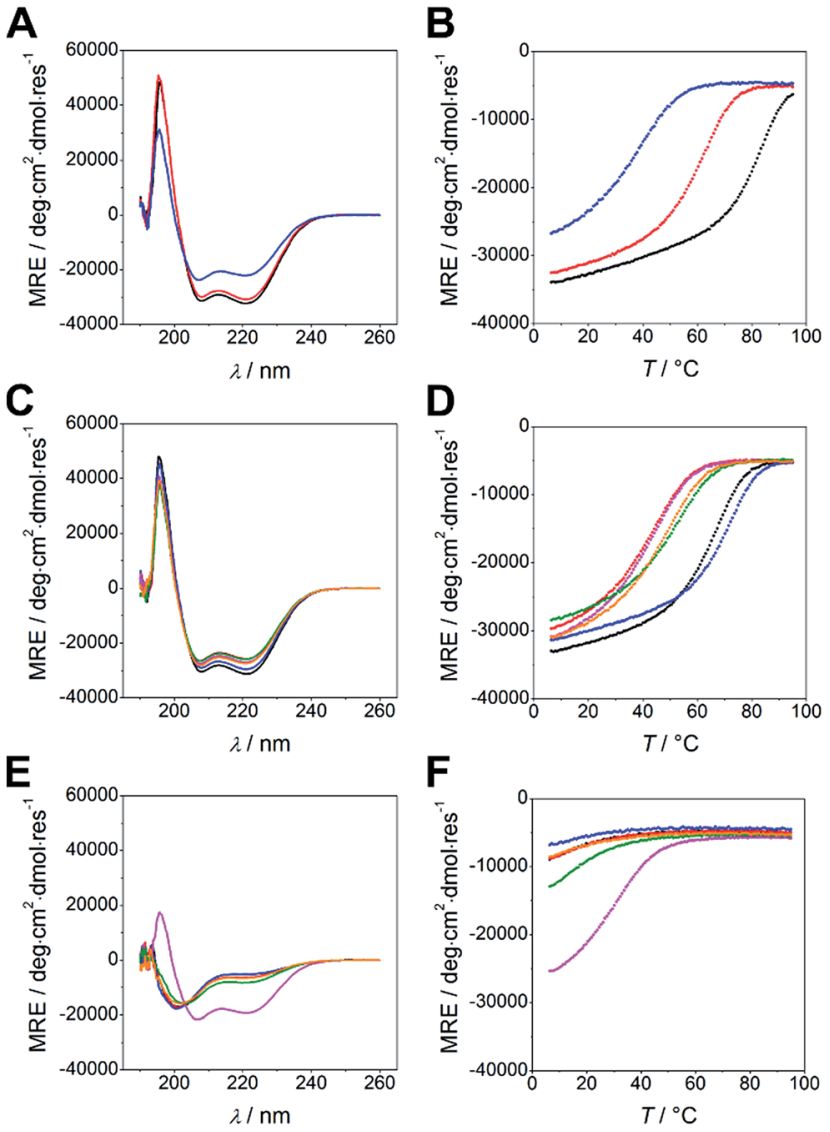

Fig. $1 C D$ spectroscopy and thermal denaturation of $C-A_{x} B_{y}$ peptides. (A) $C D$ spectra and (B) thermal denaturation curves of $C-A_{x} B_{y}$ with equal lengths of the coil strands $\left(C-A_{4} B_{4}-\right.$ black, $C-A_{3.5} B_{3.5}-$ red, $C-A_{3} B_{3}-$ blue). (C) $C D$ spectra and (D) thermal denaturation curves of $C-A_{x} B_{y}$ with different lengths of the coil strands $\left(C-A_{4} B_{3.5}-\right.$ black, $C-A_{4} B_{3}-$ red, $C-A_{3.5} B_{4}-$ blue, $C-A_{3.5} B_{3}-$ magenta, $C-A_{3} B_{4}-$ green, $C-A_{3} B_{3.5}$ - orange). (E) $C D$ spectra and (F) thermal denaturation curves of the individual peptides of $C-A_{x} B_{y}\left(C-A_{4}-\right.$ black, $C-A_{3.5}-$ red, $C-A_{3}-$ blue, $C-B_{4}-$ magenta, $C-B_{3.5}-$ green, $C-B_{3}$ - orange). $C D$ spectra were recorded at $20^{\circ} \mathrm{C}$. All data was measured in PBS at $50 \mu \mathrm{M}$ peptide concentration.

profiles were obtained as clean sigmoidal curves, from which $T_{\mathrm{M}}$ values in a range from $38^{\circ} \mathrm{C}$ for $\mathrm{C}-\mathrm{A}_{3} \mathrm{~B}_{3}$ to $81^{\circ} \mathrm{C}$ for $\mathrm{A}_{4} \mathrm{~B}_{4}$ were calculated (Fig. 1B and D). From the thermal denaturation profiles we determined the dissociation constants $K_{\mathrm{D}}$ using FitDis! 1.0 by assuming a two-state unfolding process for our heterodimeric coiled coils. ${ }^{51}$ The $K_{\mathrm{D}}$ values for $\mathrm{C}-\mathrm{A}_{x} \mathrm{~B}_{y}$ range from micromolar to sub-nanomolar concentration and are in accordance with the $K_{\mathrm{D}}$ values obtained for the $\mathrm{N}$-truncated series (Table 2 , Fig. $\mathrm{S} 2 \dagger$ ). However, $K_{\mathrm{D}}$ values of $\mathrm{N}-\mathrm{A}_{x} \mathrm{~B}_{y}$ were determined differently, more specifically, by recording a series CD-thermal-denaturation profiles across a range of peptide concentrations and linearizing the concentration-dependent melting temperatures to define the $K_{\mathrm{D}}$ at any given temperature. To ensure comparability, we decided to re-determine the $K_{\mathrm{D}}$ values of $\mathrm{N}-\mathrm{A}_{x} \mathrm{~B}_{y}$ using FitDis! 1.0 and were able to confirm a good correlation with the literature-reported values (Table 3, Fig. S1†). ${ }^{37}$ 
Table 2 Melting temperatures $\left(T_{M}\right)$ and dissociation constants $K_{\mathrm{D}}$ of $\mathrm{C}-\mathrm{A}_{x} \mathrm{~B}_{y}$ peptides $^{a}$

\begin{tabular}{|c|c|c|c|}
\hline$T_{\mathrm{M}}\left({ }^{\circ} \mathrm{C}\right) / K_{\mathrm{D}}(\mathrm{M})$ & $\mathrm{C}-\mathrm{A}_{3}$ & $\mathrm{C}-\mathrm{A}_{3.5}$ & $\mathrm{C}-\mathrm{A}_{4}$ \\
\hline $\mathrm{C}-\mathrm{B}_{3.5}$ & $48.6 \pm 0.7 /(1.5 \pm 0.3) \times 10^{-6}$ & $62.6 \pm 0.4 /(8.9 \pm 5.8) \times 10^{-8}$ & $66.5 \pm 0.4 /(5.5 \pm 2.4) \times 10^{-8}$ \\
\hline
\end{tabular}

${ }^{a} K_{\mathrm{D}} \mathrm{S}$ were determined with FitDis! 1.0 (ref. 51) from CD thermal denaturation profiles at $50 \mu \mathrm{M}$ peptide concentration except for $\mathrm{A}_{4} \mathrm{~B}_{4}$, where a CD thermal denaturation profile measured at $25 \mu \mathrm{M}$ peptide concentration was used to improve the fit.

Table 3 Dissociation constants $K_{\mathrm{D}}$ of $\mathrm{N}-\mathrm{A}_{x} \mathrm{~B}_{y}$ peptides $^{a}$

\begin{tabular}{llll}
\hline$K_{\mathrm{D}}(\mathrm{M})$ & $\mathrm{N}-\mathrm{A}_{3}$ & $\mathrm{~N}-\mathrm{A}_{3.5}$ & $\mathrm{~N}-\mathrm{A}_{4}$ \\
\hline $\mathrm{N}-\mathrm{B}_{3}$ & $(4.5 \pm 2.2) \times 10^{-6}$ & $(8.0 \pm 7.2) \times 10^{-7}$ & $(2.5 \pm 1.9) \times 10^{-7}$ \\
$\mathrm{~N}^{-} B_{3.5}$ & $(1.9 \pm 1.1) \times 10^{-6}$ & $(6.4 \pm 3.7) \times 10^{-9}$ & $(9.2 \pm 5.9) \times 10^{-10}$ \\
$\mathrm{~N}^{-} \mathrm{B}_{4}$ & $(8.8 \pm 3.5) \times 10^{-7}$ & $(1.0 \pm 1.1) \times 10^{-9}$ & $(5.7 \pm 1.1) \times 10^{-10}$
\end{tabular}

${ }^{a} K_{\mathrm{D}} \mathrm{S}$ were determined with FitDis! 1.0 (ref. 51) from CD thermal denaturation profiles at $50 \mu \mathrm{M}$ peptide concentration except for $\mathrm{A}_{4} \mathrm{~B}_{4}$, where a CD thermal denaturation profile measured at $25 \mu \mathrm{M}$ peptide concentration was used to improve the fit. $T_{\mathrm{M}}$ values have been reported by Thomas et al. ${ }^{37}$

Comparison of $T_{\mathrm{M}}$ and $K_{\mathrm{D}}$ values for $\mathrm{C}-\mathrm{A}_{x} \mathrm{~B}_{y}$ and the $\mathrm{N}$-truncated set of heterodimeric coiled coils revealed slightly reduced coiled-coil stabilities and less well distributed $K_{\mathrm{D}}$ values. For instance, the $T_{\mathrm{M}}$ and $K_{\mathrm{D}}$ of C- $\mathrm{A}_{3.5} \mathrm{~B}_{3}$ are equal to the

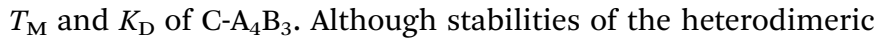
coiled coils generally increase with an increase of the length of the hydrophobic core, the lengths of the peptide overhangs at the C-termini apparently have less impact on the overall stabilities than at the N-termini. Interestingly, assemblies with B-peptide overhang are slightly more stable than assemblies, in which the A peptide is longer. This is likely due to the helix macrodipole, ${ }^{56}$ which accounts for a partially positively charged $\mathrm{N}$-terminus and a partially negatively charged C-terminus. Therefore, positively charged amino acids are structure stabilizing when located at the C-terminus and destabilizing when located at the N-terminus. The opposite effects are observed for negatively charged amino acids. If this is the case, slightly higher structure stabilities should have been found for $\mathrm{N}-\mathrm{A}_{x} \mathrm{~B}_{y}$ with longer A peptides and have indeed been reported. ${ }^{37}$

\section{The thermally more stable coiled coil is formed in CD- titration experiments}

Differences in $K_{\mathrm{D}}$ values led us to conclude that shorter coil strands could be displaced by the longer ones to give the more stable heterodimeric coiled coil. Likewise, the most stable coiled-coil assembly out of a peptide mixture of three different coil peptides should form in solution. To substantiate this hypothesis, we performed CD-titration experiments of a heterodimeric coiled coil and a competitor peptide $\left(\mathrm{P}_{\text {comp }}\right.$ : $\mathrm{A}_{\text {comp }}$, $\mathrm{B}_{\text {comp }}$ ), and analyzed the peptide mixture by $\mathrm{CD}$ spectroscopy. We determined mixtures with $\mathrm{P}_{\text {comp }}$ added in half-equimolar and equimolar amounts, respectively. In Fig. 2, the overlaid spectra of four titration experiments are exemplarily shown, namely (a) titration of $\mathrm{N}-\mathrm{B}_{3.5}$ to $\mathrm{N}-\mathrm{A}_{4} \mathrm{~B}_{3}$ and v.v. (Fig. $2 \mathrm{~A}$ and $\mathrm{B}$ ), (b) titration of $\mathrm{N}-\mathrm{A}_{3.5}$ to $\mathrm{N}-\mathrm{A}_{3} \mathrm{~B}_{4}$ and v.v. (Fig. $2 \mathrm{C}$ and D), (c)
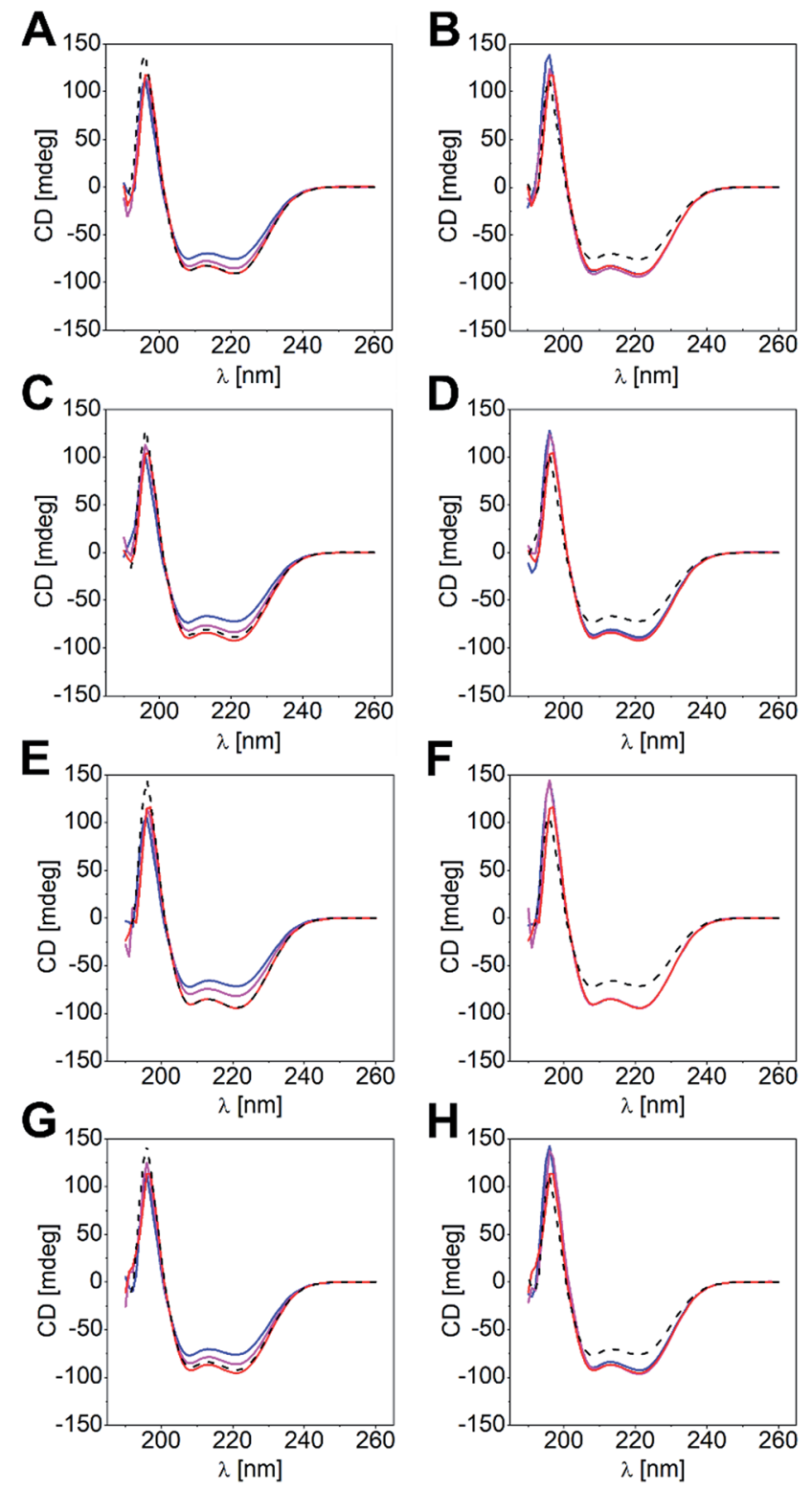

Fig. $2 C D$ spectroscopy of coiled-coil titration experiments. (A) Titration of $\mathrm{N}-\mathrm{B}_{3.5}$ to $\mathrm{N}-\mathrm{A}_{4} \mathrm{~B}_{3}$, (B) titration of $\mathrm{N}-\mathrm{B}_{3}$ to $\mathrm{N}-\mathrm{A}_{4} \mathrm{~B}_{3.5}$, (C) titration of $\mathrm{N}-\mathrm{A}_{3.5}$ to $\mathrm{N}-\mathrm{A}_{3} \mathrm{~B}_{4}$, (D) titration of $\mathrm{N}-\mathrm{A}_{3}$ to $\mathrm{N}-\mathrm{A}_{3.5} \mathrm{~B}_{4}$, (E) titration of $C-B_{3.5}$ to $C-A_{4} B_{3}$, (F) titration of $C-B_{3}$ to $C-A_{4} B_{3.5}$, (G) titration of $\mathrm{C}-\mathrm{A}_{3.5}$ to $\mathrm{C}-\mathrm{A}_{3} \mathrm{~B}_{4},(\mathrm{H})$ titration of $\mathrm{C}-\mathrm{A}_{3}$ to $\mathrm{C}-\mathrm{A}_{3.5} \mathrm{~B}_{4}$, ( 0 eq. $P_{\text {comp }}-$ blue, 0.5 eq. $P_{\text {comp }}$ - magenta, 1 eq. $P_{c o m p}-$ red, reference spectrum for complete displacement by $\mathrm{P}_{\text {comp }}$ - black, dashed line). Conditions: $50 \mu \mathrm{M} \mathrm{N} / \mathrm{C}-\mathrm{A}_{x} \mathrm{~B}_{y}, \mathrm{PBS}, 20^{\circ} \mathrm{C}$. CD data of the displaced coil peptide was used for baseline correction. 
titration of $\mathrm{C}-\mathrm{B}_{3.5}$ to $\mathrm{C}-\mathrm{A}_{4} \mathrm{~B}_{3}$ and v.v. (Fig. 2E and $\mathrm{F}$ ), and (d) titration of C-A $\mathrm{A}_{3.5}$ to $\mathrm{C}-\mathrm{A}_{3} \mathrm{~B}_{4}$ and v.v. (Fig. $2 \mathrm{G}$ and $\mathrm{H}$; for further results, see Fig. S3 and $\mathrm{S} 4 \dagger$ ). The obtained $\mathrm{CD}$ data has been corrected by the CD spectra of the supposedly displaced coil strands and compared with the CD spectra of the two competing heterodimeric coiled coils.

As clearly documented in Fig. 2, strand displacement from a coiled-coil assembly is possible in both sets of heterodimeric coiled coils, if the competing peptide interacts more strongly with the complementary coil strand (Fig. 2A, C, E and G). Titration of the respective peptides to the coiled-coil assemblies resulted in a gradual change of the CD spectra, which, in a $1: 1$ ratio of the coiled-coil assembly and the competitor peptide, superimposed well with the expected CD spectra of the more stable coiled-coil assemblies (overlay: black dotted line and red line). In contrast, titration of a shorter and more weakly interacting competitive peptide did not result in significant changes of the CD spectra.

Admittedly, the aforementioned examples reveal differences in $K_{\mathrm{D}}$ values of about two magnitudes; hence, the driving force of a strand displacement in favour for the more stable coiledcoil pair is high. However, we investigated all possible coiledcoil combinations within $\mathrm{N}-\mathrm{A}_{x} \mathrm{~B}_{y}$ and $\mathrm{C}-\mathrm{A}_{x} \mathrm{~B}_{y}$, respectively, and found that displacement of shorter coil strands by longer competing peptides is the most frequent scenario. Nonetheless, if the $K_{\mathrm{D}}$ values were very similar, the mixing experiments gave more intense CD signals, compared to the CD spectra of the two competing heterodimeric coiled-coil pairs (e.g. Fig. S3E and F or Fig. S4C and $\mathrm{D}_{\dagger}^{\dagger}$ ). Furthermore, the results were inconclusive for some combinations as the CD spectra of the competing heterodimeric coiled coils were too similar (e.g. Fig. S3M and $\mathrm{N}$ or Fig. S4Y and Z†).

\section{Strand displacement in heterodimeric coiled coils follows a competitive binding mechanism}

CD-titration experiments indicated the possibility of strand displacement in two competing coiled-coil assemblies. However, this data is purely indicative and not quantifiable. Furthermore, the experiments were performed at reasonably high peptide concentrations and do not reveal the displacement mechanism. Many applications require low peptide concentrations; hence, insights into the kinetics of strand-displacement processes in coiled coils are a requirement for reliable coiled-coil-based designs. Studying the displacement mechanism should provide information about the speed of strand displacement in two competing de novo designed heterodimeric coiled coils, and the necessary $K_{\mathrm{D}}$ difference at which to expect complete strand displacement in favour for the more stable coiled-coil assembly.

Although the coiled-coil interaction is widely understood, studies of the mechanism of strand displacement in heterodimeric coiled coils are scarce. For coiled-coil designs used in coiled-coil ligases displacement via a triple-stranded intermediate is anticipated; however, the designs are promiscuous on purpose to maintain a defined and predictable three-dimensional structure during this process. ${ }^{57}$ The heterodimeric coiled coils used herein are non-promiscuous by design, hence, higher-order oligomers during the displacement process can be excluded. We therefore assumed that displacement proceeds via a dissociative mechanism.

To approach this problem, we considered a FRET-based stranddisplacement assay using fluorescently labelled heterodimeric coiled coils as reporter peptides and non-labelled A and B peptides as competitors. As the introduction of fluorescence labels can influence the coiled-coil interaction, ${ }^{58,59}$ we decided to use small fluorescent dyes, more precisely, intrinsically fluorescent tryptophan as FRET-donor and Dansyl as FRET-acceptor. Furthermore, the chromophores were placed at a central $f$-position of the respective coiled-coil strands to avoid fluorophore-related stabilization of the overall coiled-coil assembly (Tables S1 and S2 $\dagger$ ). Generally, A peptides were labelled intrinsically with tryptophan and B peptides with Dansyl by modifying the side chain of an $f$ positioned lysine. As competitor peptides parent B peptides were suited as $\mathrm{B}_{\text {comp }}$ (Tables S1 and S2, $\uparrow$ entries 4-6), whereas for $\mathrm{A}_{\text {comp }}$ chromophore-free A peptides were synthesized (Tables S1 and S2, $\dagger$ entries 13-15).

We performed a time-resolved FRET-based displacement assay by mixing labelled A and B peptides at $15 \mu \mathrm{M}$ peptide concentration and monitoring the FRET signal as a decrease of acceptor fluorescence over $60 \mathrm{~s}$ upon injection of equimolar amounts of $\mathrm{P}_{\text {comp }}$. The obtained data was background corrected by the minimum FRET fluorescence $\left(F_{\min }\right)$, and normalized by maximum FRET fluorescence $F_{\max }$. In case of partial or complete strand displacement, a decrease of the FRET signal was observed approaching a plateau in most of the measurements. This is explained by dissociation of the preformed labelled coiled coil and re-association to a mixture of heterodimeric coiled coils depending on the rates of dissociation and association of the respective coiled-coil assemblies. The kinetic data were fit well by a single exponential model (see ESI $\dagger$ ) with observed exchange rates $\left(k_{\mathrm{obs}}\right)$ from $0.01 \mathrm{~s}^{-1}$ to $0.1 \mathrm{~s}^{-1}$ and respective half-lifes from $7 \mathrm{~s}$ to $70 \mathrm{~s}$ (Tables $\mathrm{S} 5$ and $\mathrm{S} 6 \dagger$ ). In Fig. 3A-D the strand-displacement kinetics of $\mathrm{N}-\mathrm{A}_{3} \mathrm{~B}_{4}-\mathrm{A}_{\text {comp }}, \mathrm{N}$ $\mathrm{A}_{3.5} \mathrm{~B}_{4}-\mathrm{B}_{\text {comp }}, \mathrm{C}-\mathrm{A}_{3} \mathrm{~B}_{4}-\mathrm{A}_{\text {comp }}$, and $\mathrm{C}-\mathrm{A}_{3.5} \mathrm{~B}_{4}-\mathrm{B}_{\text {comp }}$ are shown. It is clearly noticeable that strand displacement is more likely with larger difference in $K_{\mathrm{D}}$. The length of the competitor strand is less important as demonstrated by displacement of the $\mathrm{B}_{4}$-coil

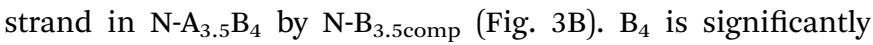
displaced although $\mathrm{N}-\mathrm{B}_{3.5 \text { comp }}$ is shorter. However, the $K_{\mathrm{D}}$ value

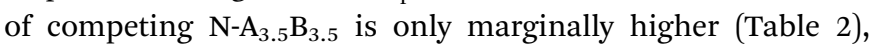
hence, at equilibrium, a mixture of both assemblies is present.

The kinetic data from the FRET assay revealed an equilibrium reaction for strand displacement in heterodimeric coiled coils, which is interpreted as a competition of $\mathrm{P}_{\text {comp }}$ and the respective coil strand for association to the complementary coil strand. As mentioned above, we hypothesized a dissociative mechanism for the strand displacement. We assumed that a competition model should describe strand displacement in good approximation, although coiled-coil interaction is obligate. Therefore, the measured kinetic data were fitted to competitive binding mechanism using the program DynaFit. ${ }^{52,53}$ As changes in concentration of free displaced (forward reaction) and replaced (backward reaction) A or B peptide are fit, we converted the FRET-acceptor fluorescence signal to 
$\mathbf{A}$

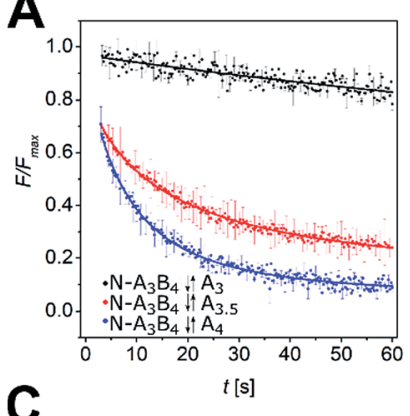

C
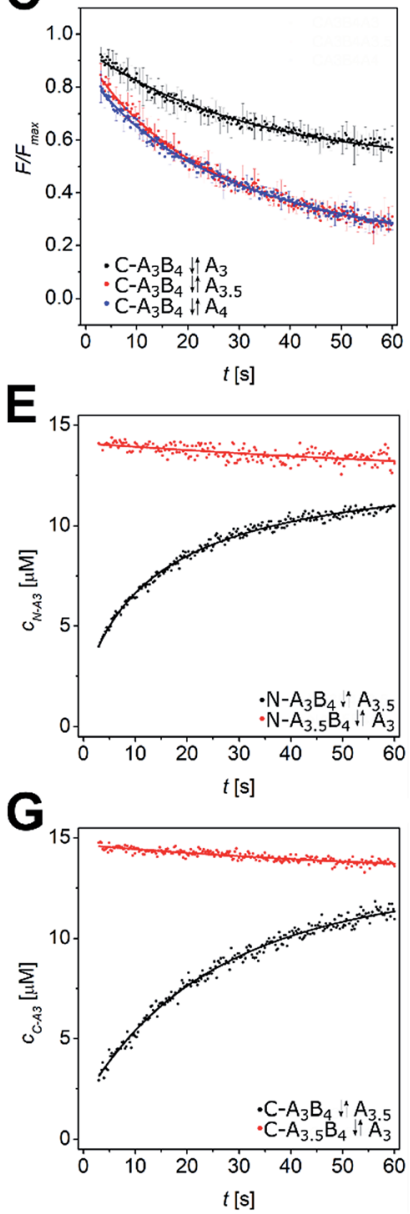

B

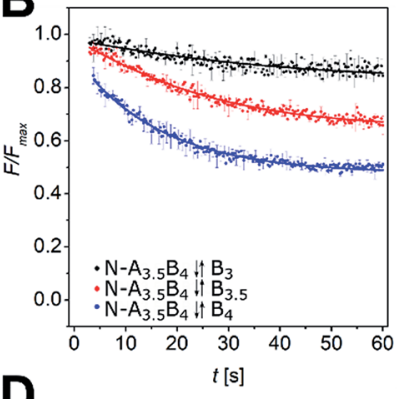

D
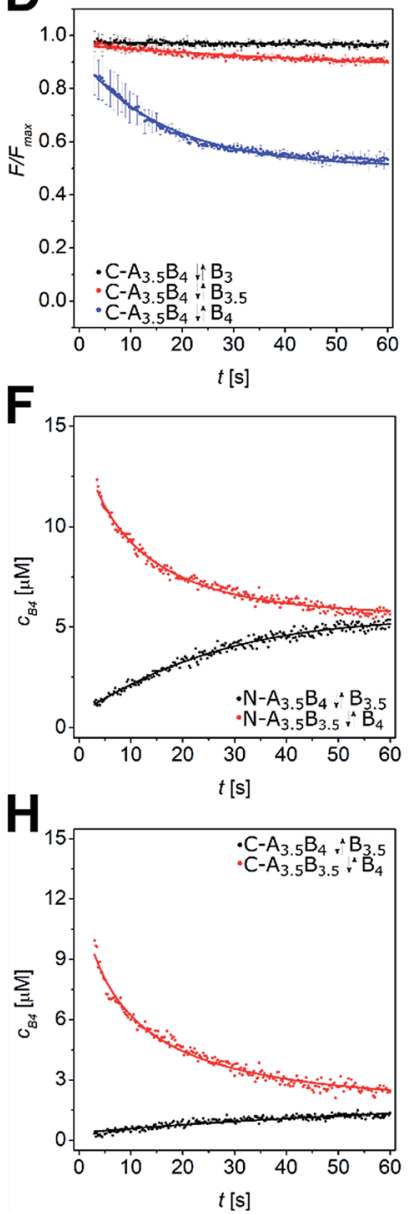

Fig. 3 Strand-displacement kinetics in heterodimeric coiled coils. (A-D) Normalized time-resolved fluorescence decrease upon strand displacement in $A_{x} B_{y}$ peptides. Exemplarily, strand displacements in $\mathrm{N}$ $A_{3} B_{4}$ by $N-A_{\text {comp }}(A), N-A_{3.5} B_{4}$ by $N-B_{\text {comp }}(B), C-A_{3} B_{4}$ by $C-A_{\text {comp }}(C)$, and $C-A_{3.5} B_{4}$ by $C-B_{\text {comp }}(D)$ are shown. Data is fit by a single exponential decay model. (E-H) Least-squares fits of strand displacement in $\mathrm{N}-\mathrm{A}_{3} \mathrm{~B}_{4}$ by $\mathrm{A}_{3.5}(\mathrm{E}), \mathrm{N}-\mathrm{A}_{3.5} \mathrm{~B}_{4}$ by $\mathrm{B}_{3.5}(\mathrm{~F}), \mathrm{C}-\mathrm{A}_{3} \mathrm{~B}_{4}$ by $\mathrm{A}_{3.5}(\mathrm{G})$, and $\mathrm{C}-\mathrm{A}_{3.5} \mathrm{~B}_{4}$ by $\mathrm{B}_{3.5}(\mathrm{H})$ using a competitive binding model in DynaFit ${ }^{53}$ (forward reaction - black, backward reaction - red). Conditions: $15 \mu \mathrm{M}$ peptide concentration, PBS ( $\mathrm{pH} 7.4)$, room temperature, readout: $\lambda_{\mathrm{ex}}=$ $270 \mathrm{~nm}, \lambda_{\mathrm{em}}=540 \mathrm{~nm}$. Measurements were performed as triplicates.

peptide concentration to generate the input files required for DynaFit as described in the Materials and methods section. Simultaneous fitting of both events, displacement of A or B from the initial $\mathrm{AB}$ coiled coil and reassociation, gave rate constants $k_{1}$ to $k_{4}$ from which the overall affinities $\left(k_{1} k_{4} / k_{2} k_{3}\right)$
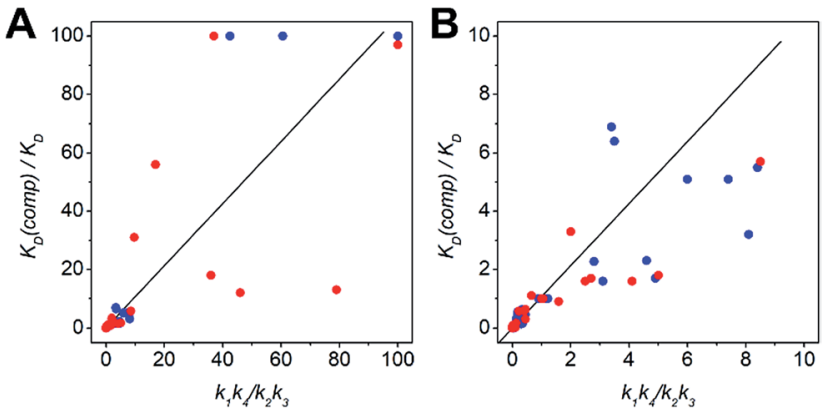

Fig. 4 Scatter plots depicting the correlation between the ratio of $K_{D}$ values and overall affinities. (A) Scatter plot including ratios upto 100 . (B) Low-range scatter plot (colour-key: $N-A_{x} B_{y}-$ blue, $C-A_{x} B_{y}-$ red). The $K_{\mathrm{D}}$ values were determined by $\mathrm{CD}$-thermal denaturation experiments. The overall affinities $\left(k_{1} k_{4} / k_{2} k_{3}\right)$ result from processing of the kinetic data to a competitive binding mechanism in DynaFit. For clarity, ratios $>100$ are not depicted in the plots. This data is shown in Tables S7 and S8.†

were calculated (Tables S7 and S8†). As exemplarily shown in Fig. 3, the competitive binding model applied well to the stranddisplacement data and the obtained overall affinities showed a good correlation to the ratio of $K_{\mathrm{D}}$ values obtained from CD thermal denaturation curves (Fig. 4, Tables S7 and S8 †). This supports the competition model for strand displacement in heterodimeric coiled coils. The ratio of the $K_{\mathrm{D}}$ values of the two competing coiled coils should give the equilibrium concentration and therefore, should be suitable to predict the outcome of a displacement reaction.

We performed more than 100 displacement reactions, from which we were able to deduce an assignment of the obtained values. In Fig. 3E-H four typical graphical outputs of our DynaFit data analysis are shown with the black traces depicting the forward reactions and the red traces the backward reactions. Except for $\mathrm{N}-\mathrm{A}_{3.5} \mathrm{~B}_{3.5}-\mathrm{B}_{4}$ (Fig. $3 \mathrm{~F}$ ) the positions of stranddisplacement equilibria lie either fully on the side of the strand-displacement products (Fig. 3E and G) or on the side of the strand-displacement educts (Fig. $3 \mathrm{H}$ ). If this is the case, the overall affinities gave either values less than 0.1 for complete or almost complete strand displacement or greater than 10.0 for no or only little strand displacement. If strand displacement reaction resulted in a mixture of both competing heterodimeric coiled coils at equilibrium (Fig. 3F), overall affinities gave values between 10.0 and 0.1 . We state that these ranges of overall affinities or $K_{\mathrm{D}}$ values can be applied as a reliable rule-of-thumb to assess strand-displacement equilibria in any competing heterodimeric coiled coils, if the assemblies are non-promiscuously heterodimeric.

\section{Conclusion}

In summary, we have presented a thorough study on single strand-displacement kinetics in de novo designed parallel heterodimeric coiled coils. We investigated two sets of wellcharacterized heterodimeric coiled coils, which exhibit dissociation constants from the $\mu \mathrm{M}$ to the sub-nM regime. Peptide 
design is based on Hodges EK peptides, ${ }^{31}$ but is extended by Asn residues at a central $a$ position to increase the specificity for parallel-oriented dimeric assemblies. Furthermore, this additional design feature allows formation of defined coiled-coil assemblies with variable chain lengths, a key-requirement for easy modulation of the strength of coiled-coil association. Design and biophysical characterization of the $\mathrm{N}-\mathrm{A}_{x} \mathrm{~B}_{y}$ peptides have been previously reported. ${ }^{37}$ Variation of $K_{\mathrm{D}}$ values was achieved by truncating the individual coiled-coil strands from the N-terminal end. We expanded the existing set of wellcharacterized heterodimeric coiled coils by adding $\mathrm{C}-\mathrm{A}_{x} \mathrm{~B}_{y}$, which is based on the same design rules as $N-A_{x} B_{y}$, except the fine-tuning of the strength of association is achieved by truncating the individual coil strands from the C-terminal end. We consider $\mathrm{C}-\mathrm{A}_{x} \mathrm{~B}_{y}$ as a useful addition to the coiled-coil toolkit as blunt-ended $\mathrm{N}$-termini facilitate applications, in which $\mathrm{N}$-terminal modified coiled coils are involved. $\mathrm{C}-\mathrm{A}_{x} \mathrm{~B}_{y}$ peptides were characterized by $\mathrm{CD}$ spectroscopy, and $K_{\mathrm{D}}$ values were determined from CD-thermal-denaturation profiles. Although the resulting assemblies showed an overall slightly reduced stability compared to $\mathrm{N}-\mathrm{A}_{x} \mathrm{~B}_{y}$ the determined $K_{\mathrm{D}}$ values covered a similar range of concentrations.

We studied strand displacement in both sets of heterodimeric coiled coils. CD-titration experiments indicated a preference for the formation of the thermodynamically more stable coiled coil in most of the studied combinations. However, coiled-coil mixtures with similar $K_{\mathrm{D}}$ values of the two competing assemblies gave inconclusive CD data. Using a FRET-based assay, we characterized strand displacements in our sets of heterodimeric coiled coils as equilibrium reactions with halflifes of about 7 to $70 \mathrm{~s}$. The kinetic data were fit well by a competitive binding model from which the rate constants of association and dissociation of the competing coiled-coil assemblies, and hence, the overall affinities were obtained. The overall affinities correlate well with the respective ratio of $K_{\mathrm{D}}$ values obtained from CD data supporting the competitive binding mechanism of the strand displacement in heterodimeric coiled coils.

The ratio of $K_{\mathrm{D}}$ values can be used to predict the outcome of a strand-displacement reaction. Based on the results of 108 possible strand-displacement reactions, we were able to correlate the ratio of $K_{\mathrm{D}}$ values to the position of the stranddisplacement equilibrium and to classify three categories: $K_{\mathrm{D}}$ ratios of above 10.0 correlate with very slow to no strand displacement, whereas ratios below 0.1 indicate complete displacement reactions. With ratios of $K_{\mathrm{D}}$ values between 10.0 and 0.1 the formation of coiled-coil mixtures is highly probable.

Our aim was to find a reliable rule to assess strand displacement in heterodimeric coiled coils. Very often the $K_{\mathrm{D}}$ values of coiled coils are known and discussed as potential parameters to predict strand displacement. ${ }^{8,37}$ Best to our knowledge, there is only one very recent study that correlates $K_{\mathrm{D}}$ differences and strand displacement; ${ }^{49}$ however, only selected coiled coils were investigated and an analysis of the underlying mechanism has not been undertaken. Furthermore, the coiled coils applied in that study have previously been proven to form promiscuous assemblies as they are lacking the required core- asparagine residues. ${ }^{35-37}$ We studied an extended coiled-coil library and thus were able to identify the reaction mechanism, which allows us to use the ratio of $K_{\mathrm{D}}$ values of the competing coiled coils as parameter to reliably predict the outcome of a strand-displacement reaction without further kinetic experiments. We believe that the abovementioned rule of thumb is easy to adapt to other sets of heterodimeric coiled coils based on similar designs, and hence, will facilitate future designs of dynamic coiled-coil-based systems.

\section{Conflicts of interest}

There are no conflicts to declare.

\section{Acknowledgements}

The project was funded by the German Research Foundation (DFG, TH 2008/2-1) and the Fonds der Chemischen Industrie (FCI). We are grateful to Prof. Dr Ulf Diederichsen for scientific support and general access to technical equipment.

\section{References}

1 A. L. Boyle and D. N. Woolfson, Chem. Soc. Rev., 2011, 40, 4295.

2 G. A. Khoury, J. Smadbeck, C. A. Kieslich and C. A. Floudas, Trends Biotechnol., 2014, 32, 99-109.

3 A. N. Lupas and J. Bassler, Trends Biochem. Sci., 2017, 42, 130-140.

4 H. Robson Marsden and A. Kros, Angew. Chem., Int. Ed., 2010, 49, 2988-3005.

5 A. N. Lupas, J. Bassler and S. Dunin-Horkawicz, in SubCellular Biochemistry, ed. D. A. D. Parry and J. M. Squire, Springer International Publishing, Cham, 2017, pp. 95-129.

6 D. N. Woolfson, G. J. Bartlett, A. J. Burton, J. W. Heal, A. Niitsu, A. R. Thomson and C. W. Wood, Curr. Opin. Struct. Biol., 2015, 33, 16-26.

7 D. N. Woolfson, Fibrous Proteins Struct. Mech., 2017, vol. 82, pp. 35-61.

8 K. E. Thompson, C. J. Bashor, W. A. Lim and A. E. Keating, ACS Synth. Biol., 2012, 1, 118-129.

9 I. Nakase, S. Okumura, G. Tanaka, K. Osaki, M. Imanishi and S. Futaki, Angew. Chem., Int. Ed., 2012, 51, 7464-7467.

10 H. Robson Marsden, N. A. Elbers, P. H. H. Bomans, N. A. J. M. Sommerdijk and A. Kros, Angew. Chem., Int. Ed., 2009, 48, 2330-2333.

11 K. Meyenberg, A. S. Lygina, G. van den Bogaart, R. Jahn and U. Diederichsen, Chem. Commun., 2011, 47, 9405.

12 Y. Yano, A. Yano, S. Oishi, Y. Sugimoto, G. Tsujimoto, N. Fujii and K. Matsuzaki, ACS Chem. Biol., 2008, 3, 341-345.

13 Y. Takeda, Y. Yano and K. Matsuzaki, Anal. Chem., 2012, 84, 1754-1759.

14 B. Tripet, L. Yu, D. L. Bautista, W. Y. Wong, R. T. Irvin and R. S. Hodges, Protein Eng., Des. Sel., 1996, 9, 1029-1042.

15 C. Boucher, G. St-Laurent, M. Jolicoeur, G. De Crescenzo and Y. Durocher, Anal. Biochem., 2010, 399, 138-140. 
16 E. F. Banwell, E. S. Abelardo, D. J. Adams, M. A. Birchall, A. Corrigan, A. M. Donald, M. Kirkland, L. C. Serpell, M. F. Butler and D. N. Woolfson, Nat. Mater., 2009, 8, 596-600. 17 J. M. Fletcher, R. L. Harniman, F. R. H. Barnes, A. L. Boyle, A. Collins, J. Mantell, T. H. Sharp, M. Antognozzi, P. J. Booth, N. Linden, M. J. Miles, R. B. Sessions, P. Verkade and D. N. Woolfson, Science, 2013, 340, 595-599.

18 A. L. Boyle, E. H. C. Bromley, G. J. Bartlett, R. B. Sessions, T. H. Sharp, C. L. Williams, P. M. G. Curmi, N. R. Forde, H. Linke and D. N. Woolfson, J. Am. Chem. Soc., 2012, 134, 15457-15467.

19 H. Gradišar, S. Božič, T. Doles, D. Vengust, I. HafnerBratkovič, A. Mertelj, B. Webb, A. Šali, S. Klavžar and R. Jerala, Nat. Chem. Biol., 2013, 9, 362-366.

20 W. M. Park, M. Bedewy, K. K. Berggren and A. E. Keating, Sci. Rep., 2017, 7, 1-10.

21 C. Xu, R. Liu, A. K. Mehta, R. C. Guerrero-Ferreira, E. R. Wright, S. Dunin-Horkawicz, K. Morris, L. C. Serpell, X. Zuo, J. S. Wall and V. P. Conticello, J. Am. Chem. Soc., 2013, 135, 15565-15578.

22 F. Thomas, N. C. Burgess, A. R. Thomson and D. N. Woolfson, Angew. Chem., Int. Ed., 2016, 55, 987-991.

23 N. C. Burgess, T. H. Sharp, F. Thomas, C. W. Wood, A. R. Thomson, N. R. Zaccai, R. L. Brady, L. C. Serpell and D. N. Woolfson, J. Am. Chem. Soc., 2015, 137, 10554-10562.

24 K. Severin, D. H. Lee, A. J. Kennan and M. R. Ghadiri, Nature, 1997, 389, 706-709.

25 Z.-Z. Huang, L. J. Leman and M. R. Ghadiri, Angew. Chem., Int. Ed., 2008, 47, 1758-1761.

26 U. Reinhardt, J. Lotze, S. Zernia, K. Mörl, A. G. BeckSickinger and O. Seitz, Angew. Chem., Int. Ed., 2014, 53, 10237-10241.

27 Y. Yano, N. Furukawa, S. Ono, Y. Takeda and K. Matsuzaki, Biopolymers, 2016, 106, 484-490.

28 B. V. Popp and Z. T. Ball, J. Am. Chem. Soc., 2010, 132, 66606662.

29 P. Harbury, T. Zhang, P. Kim and T. Alber, Science, 1993, 262, 1401-1407.

30 E. K. O'Shea, K. J. Lumb and P. S. Kim, Curr. Biol., 1993, 3, 658-667.

31 J. R. Litowski and R. S. Hodges, J. Biol. Chem., 2002, 277, 37272-37279.

32 P. Lavigne, C. M. Kay, F. D. Sönnichsen, R. S. Hodges, K. J. Lumb and P. S. Kim, Science, 1996, 271, 1136-1138.

33 K. J. Lumb and P. S. Kim, Science, 1996, 271, 1137-1138.

34 D. N. Marti and H. R. Bosshard, Biochemistry, 2004, 43, 12436-12447.

35 J. M. Fletcher, A. L. Boyle, M. Bruning, G. J. Bartlett, T. L. Vincent, N. R. Zaccai, C. T. Armstrong,
E. H. C. Bromley, P. J. Booth, R. L. Brady, A. R. Thomson and D. N. Woolfson, ACS Synth. Biol., 2012, 1, 240-250.

36 J. M. Fletcher, G. J. Bartlett, A. L. Boyle, J. J. Danon, L. E. Rush, A. N. Lupas and D. N. Woolfson, ACS Chem. Biol., 2017, 12, 528-538.

37 F. Thomas, A. L. Boyle, A. J. Burton and D. N. Woolfson, J. Am. Chem. Soc., 2013, 135, 5161-5166.

38 M. G. Oakley and P. S. Kim, Biochemistry, 1998, 37, 1260312610.

39 F. Thomas, A. Niitsu, A. Oregioni, G. J. Bartlett and D. N. Woolfson, Biochemistry, 2017, 56, 6544-6554.

40 H. Gradisar and R. Jerala, J. Pept. Sci., 2011, 17, 100-106.

41 E. H. C. Bromley, K. Channon, E. Moutevelis and D. N. Woolfson, ACS Chem. Biol., 2008, 3, 38-50.

42 G. Grigoryan and A. E. Keating, J. Mol. Biol., 2006, 355, 11251142.

43 M. L. Diss and A. J. Kennan, J. Am. Chem. Soc., 2008, 130, 1321-1327.

44 R. O. Crooks, A. Lathbridge, A. S. Panek and J. M. Mason, Biochemistry, 2017, 56, 1573-1584.

45 F. Murschel, C. Fortier, M. Jolicoeur, R. S. Hodges and G. De Crescenzo, Biomacromolecules, 2017, 18, 965-975.

46 S. J. Ryan and A. J. Kennan, J. Am. Chem. Soc., 2007, 129, 10255-10260.

47 C. Aronsson, S. Dånmark, F. Zhou, P. Öberg, K. Enander, H. Su and D. Aili, Sci. Rep., 2015, 5, 14063.

48 G. De Crescenzo, J. R. Litowski, R. S. Hodges and M. D. O'Connor-McCourt, Biochemistry, 2003, 42, 1754-1763.

49 K. Gröger, G. Gavins and O. Seitz, Angew. Chem., Int. Ed., 2017, 56, 14217-14221.

50 B. J. H. Kuipers and H. Gruppen, J. Agric. Food Chem., 2007, 55, 5445-5451.

51 M. Rabe, A. Boyle, H. R. Zope, F. Versluis and A. Kros, Biopolymers, 2015, 104, 65-72.

52 P. Kuzmic, Anal. Biochem., 1996, 237, 260-273.

53 P. Kuzmic, Anal. Biochem., 1999, 267, 17-23.

54 J. Y. Su, R. S. Hodges and C. M. Kay, Biochemistry, 1994, 33, 15501-15510.

55 Y. Wu and J. H. Collier, Wiley Interdiscip. Rev.: Nanomed. Nanobiotechnol., 2017, 9, e1424.

56 S. Walter, B. Hubner, U. Hahn and F. X. Schmid, J. Mol. Biol., 1995, 252, 133-143.

57 Z. Dadon, N. Wagner, S. Alasibi, M. Samiappan, R. Mukherjee and G. Ashkenasy, Chem.-Eur. J., 2015, 21, 648-654.

58 D. L. Daugherty and S. H. Gellman, J. Am. Chem. Soc., 1999, 121, 4325-4333.

59 M. D. Watson, I. Peran and D. P. Raleigh, Biochemistry, 2016, 55, 3685-3691. 